\title{
Mixed messages
}

Cite as: CMAJ 2022 February 22;194:E264-5. doi: 10.1503/cmaj.1095987

Posted on cmajnews.com on February 4, 2022

$\mathrm{T}$ he past year has been marked by growing friction between pandemic policy and the advice of some vocal front-line health workers.

These physicians say they're speaking out because of eroding trust in government decisions. They also see their advocacy as having an impact - even if changes are coming later than they'd like. Others, meanwhile, question if the fracturing of public health messaging is serving Canadians.

Early in 2021, relief over the approval of COVID-19 vaccines gave way to frustration over access to the shots.

In the spring, Ontario Premier Doug Ford had been easing pandemic restrictions, despite projections showing escalating intensive care admissions, as well as calls for the province to target vaccines to the hardest-hit neighbourhoods.

Dr. Michael Warner shared his anger and grief over the death of a Toronto woman in her forties whose factory worker husband brought home SARS-CoV-2 because he couldn't take time off when his workplace had an outbreak.

"Only the people who are truly essential should be working and we should be doing everything to protect them," Warner urged in an emotional interview. "Vaccinate everyone in Scarborough, everyone in Peel, everyone in North Etobicoke, everyone in Jane and Finch... because that's where the people live who are dying."

Over the next few weeks, the Ontario government imposed a province-wide lockdown, prioritized vaccinations for "hotspot" neighbourhoods and approved a paid sick leave program.

In the summer, Alberta's decision to drop all pandemic restrictions led to health workers picketing government buildings and a crisis of confidence in the province's chief medical officer when infections resurged.

In the late summer and fall, independent experts in Alberta and British Columbia organized under the slogan "Protect Our Province" to issue their own pandemic briefings in response to what they saw as a lack of transparency in official communications. At the time, Alberta's government hadn't held any COVID-19 briefings in weeks despite rising case counts and hospitalizations.

And 2022 brought new disillusionment among some health workers over shortened isolation periods, governments giving up on testing and contact tracing, and the slow response to Omicron hospitalizations.

\section{Breaking from "behind the scenes" advocacy}

Dr. Neeja Bakshi, a spokesperson for Protect Our Province Alberta, says that launching their own pandemic briefings appeared to get the government's attention - and not only because the province moved official updates to the same time.

The group's videos have earned tens of thousands of views and encouraged journalists to press for information, including about how the government is addressing the current hospital capacity crisis. (The Alberta Ministry of Health did not respond to requests for comment.)

Dr. Amy Tan, a family physician and palliative care doctor who advocates with Protect Our Province British Columbia, says she wanted to speak directly to the public to counter what she saw as "gaslighting and toxic positivity" about the realities of the pandemic - such as when B.C. Health Minister Adrian Dix told reporters that hospitals had more beds available than before the pandemic.
"It's not about a lack of beds, but a lack of staff," Tan says. "At what point does health care workers' tap run out?"

For Dr. Tamara Hinz, a psychiatrist in Saskatoon, social media advocacy has been an important outlet for preventing moral injury in the face of official narratives about the pandemic that sometimes felt "so blatantly incorrect and so unfair."

For example, Hinz felt it was a "slap in the face" when Saskatchewan Premier Scott Moe called on medical professionals in the fall of 2021 to dispel COVID misinformation - as if they weren't doing so already.

To "set the public record straight," Hinz posted a Twitter thread of the multiple open letters that health workers had written to Moe's government during the pandemic - including recommendations from Saskatchewan's 17 medical officers of health that Hinz says the premier ignored initially before changing course weeks later.

The pandemic has shown many health workers the power of taking their concerns public, Hinz says, in a break from how physician advocacy has typically happened "behind the scenes" in the past.

Even after the pandemic, "I think elements of that will stay," she says.

Dr. David Fisman, a professor of epidemiology at the University of Toronto, has found that advocating on social media has been more effective than going through official channels.

"I talked about airborne transmission of COVID to the Council of Chief Medical Officers of Health in September 2020. That went exactly nowhere, in terms of policy," Fisman says. He believes he had a greater impact by aligning with scientists from other disciplines and sharing information about airborne transmission in the news and on social media. 


\section{Conflict and confusion}

In August, Fisman resigned from Ontario's COVID-19 Science Advisory Table, noting that he was "increasingly uncomfortable with the degree to which political considerations appear to be driving outputs from the table or at least the degree to which these outputs are shared in a transparent matter with the public."

Other representatives of the advisory group explained that coming to a consensus on the evidence isn't a process they can rush, and they release data only when they have reviewed a range of models to ensure that the information is reliable.

Fisman, who strongly advocated for additional health measures in schools, has faced scrutiny over his consulting work for the Elementary Teachers' Federation of Ontario. He has also received death threats and "lost quite a number of friendships."

However, Fisman says he feels a responsibility to speak out because he has a "secure platform" as a tenured professor, while others might face professional repercussions.

Independent experts aren't alone in experiencing escalating abuse related to the pandemic. Public health officials across the country have been flooded with hate mail, faced protests at their homes, and are increasingly seeking legal recourse against harassment.

Josh Greenberg, director of the School of Journalism and Communication at Carleton University, has noticed the polarization in messaging from governments and some independent health experts.

According to Greenberg, "it's not inappropriate for experts to take critical positions against governments they feel have failed in their duty to protect the public interest."
However, he worries that when public health communications become "overly adversarial, even toxic" it has the potential of "creating a distorted picture of how experts and decision-makers communicate, especially in times of crisis."

Greenberg explains that people may assume that the government doesn't consult experts at all, even when they do, which could erode trust in the government and in experts generally if the public perceives they are "overstepping" their roles.

Dr. Lynora Saxinger, an infectious disease physician and associate professor at the University of Alberta, also worries that clashes between governments and health professionals could cause "undue, excessive anxiety and mistrust."

According to Saxinger, places that have done well in the pandemic, such as New Zealand and Taiwan, "have had good communication and good buy-in from the population."

She adds that anything that implies health experts or politicians are "doing things with ill intent... always raises alarm bells for me of bias."

\section{Bridging the divide}

Some governments haven't helped the situation by maintaining their pre-pandemic practice of keeping health policy deliberations behind closed doors.

Rather than seeing messaging from policy-makers and independent experts split into "these two channels where it feels like there's a wall between them," Saxinger says she'd prefer to see more "transparency around the evidence base presented and the government rationale for decisions."
Meanwhile, health workers can bridge politically polarized debate by grounding advocacy in their personal experiences, Saxinger says. "When people say, 'This is what I'm seeing in the hospital,' that makes a big difference to public perception because it's not seen as political."

For Warner, sharing stories about the impact of pandemic policies on his patients is part of what it means to be a physician. "The CanMEDS roles prioritize being both a medical expert and a health advocate," he says. "What I have been doing is advocacy."

Like Fisman, Warner has faced threats to his safety, including receiving a suspicious package at work. He says professional organizations and regulatory bodies should do more to support physicians navigating their role as advocates, including by providing guidance on how to protect themselves and their careers.

Warner says the lack of support from medical organizations and regulators is especially worrying because "if you look at the people who have stuck their necks out, they are not the CEOs of hospitals, the hospital chiefs, nor well-known, senior academic clinicians, by and large - they are early- to mid-career physicians."

\section{Wendy Glauser, Toronto, Ont.}

Content licence: This is an Open Access article distributed in accordance with the terms of the Creative Commons Attribution (CC BY-NC-ND 4.0) licence, which permits use, distribution and reproduction in any medium, provided that the original publication is properly cited, the use is noncommercial (i.e., research or educational use), and no modifications or adaptations are made. See: https://creativecommons.org/ licenses/by-nc-nd/4.0/ 